\title{
Chronic rhinosinusitis with nasal polyps in the elderly
}

\author{
Marjolein Cornet ${ }^{1 *}$, Wytske Fokkens ${ }^{2}$ \\ From 9th Symposium of Experimental Rhinology and Immunology of the Nose (SERIN 2013) \\ Leuven, Belgium. 21-23 March 2013
}

\section{Background}

To determine the influence of age on the long term results of functional endoscopic sinus surgery (FESS) in patients with chronic rhinosinusitis with nasal polyps (CRSwNP).

\section{Methods}

In this study we sent all adult patients who received FESS because of CRSwNP between the year 2000 and 2005 in the AMC in Amsterdam a quality of life questionnaire in the year 2012. The Lund-Mackay score was calculated for each patient. We compared postoperative subjective improvement using the SNOT questionnaire. Two different age groups were analysed separately, group 1 (age 18-65) and group 2 (over 65 years).

\section{Results}

Response rate was 67\% (151 out of 225). 104 patients were $<65$ years old (group 1) and 47 patients $>65$ years (group 2). The mean age at the time of questionnaire of the whole group was 56 years old (range 28-84). Mean follow-up time was 7 years (range 12 years). Of these patients $35 \%$ had a primary FESS and $65 \%$ revision surgery. There was no statistical difference in LundMackay score between the two age groups. The mean postoperative total SNOT score in the whole group was 1.3. We found a tendency to significance with a lower score in the older age group compared to the younger patients $(\mathrm{p}=0.06)$ and in several separate SNOT domain scores we found a significant difference. The older patients scored significantly lower in the domains of ear- and head symptoms.

${ }^{1}$ AMC, Amsterdam, the Netherlands

Full list of author information is available at the end of the article

\section{Conclusion}

Our subjective postoperative outcomes show a significant difference in several SNOT domains and a tendency to significance in total SNOT score between the two different age groups. These results could be influenced by a natural decrease in symptoms over time in older patients. There is still not enough evidence for this thought and further research will be needed on this subject.

\section{Author details}

${ }^{1}$ AMC, Amsterdam, the Netherlands. ${ }^{2}$ AMC, Otorhinolaryngology, Amsterdam, the Netherlands.

Published: 16 July 2013

\section{doi:10.1186/2045-7022-3-S2-P35}

Cite this article as: Cornet and Fokkens: Chronic rhinosinusitis with nasal polyps in the elderly. Clinical and Translational Allergy 2013 3(Suppl 2):P35.

Submit your next manuscript to BioMed Central and take full advantage of:

- Convenient online submission

- Thorough peer review

- No space constraints or color figure charges

- Immediate publication on acceptance

- Inclusion in PubMed, CAS, Scopus and Google Scholar

- Research which is freely available for redistribution 